\title{
Clinical effect of vitamin D supplementation on patients with pulmonary tuberculosis and its influence on the expression of immune cells and inflammatory factors
}

\author{
CHUNXU CHENG ${ }^{1}$, WEINA PAN ${ }^{1}, \mathrm{XIANG} \mathrm{LI}^{2}$ and HONGYAN QU ${ }^{3}$ \\ ${ }^{1}$ Department of Infectious Diseases, Changchun Hospital for Infectious Diseases, Changchun, Jilin 130031; \\ ${ }^{2}$ Department of Radiology, The Third People's Hospital of Gongzhuling City, Siping, Jilin 136105; ${ }^{3}$ Department of \\ Drug-Resistant Tuberculosis, Changchun Hospital for Infectious Diseases, Changchun, Jilin 130031, P.R. China
}

Received January 21, 2020; Accepted May 21, 2020

DOI: $10.3892 /$ etm.2020.8957

\begin{abstract}
Tuberculosis is highly infectious and has a high incidence worldwide. Therefore, effective treatment is essential for the disease. The immune function and inflammatory factors can reflect the therapeutic effect of pulmonary tuberculosis to some extent. Thus, the aim of the present study was to investigate the clinical effect of vitamin D supplementation on pulmonary tuberculosis patients and its influence on the expression of immune cells and inflammatory factors in patients. A total of 256 patients with pulmonary tuberculosis who were admitted to our hospital were collected as research participants; 120 patients who were treated with conventional antituberculosis drugs were taken as a control group (CG) and 136 patients who were treated with vitamin D-assisted antituberculosis drugs were taken as the research group (RG). The levels of inflammatory factors (IL-6, MMP-9, IL-4, TNF- $\alpha$ ) and $\mathrm{T}$ lymphocyte subgroup of patients were measured in both groups before and after treatment. The efficacy was compared in both groups. The disappearance time of wheezing and cough in RG was shorter than that in $\mathrm{CG}(\mathrm{P}<0.001)$. There was no difference in X-ray chest plain film, sputum examination results and efficacy of patients in both groups $(\mathrm{P}>0.05)$. After treatment, $\mathrm{CD}^{+}, \mathrm{CD}^{+}, \mathrm{CD}^{+} / \mathrm{CD}^{+}$were upregulated in both groups $(\mathrm{P}<0.05)$, while $\mathrm{CD}^{+}, \mathrm{CD}^{+}, \mathrm{CD}^{+} / \mathrm{CD}^{+}$in RG were higher than those in $\mathrm{CG}(\mathrm{P}<0.05)$. After treatment, inflammatory factors in both groups improved compared with those before treatment. Serum inflammatory factors in RG were significantly lower than those in $\mathrm{CG}(\mathrm{P}<0.05)$. After treatment, surfactant protein in the two groups was lower than
\end{abstract}

Correspondence to: Dr Hongyan Qu, Department of Drug-Resistant Tuberculosis, Changchun Hospital for Infectious Diseases, 2699 3rd Road, Section South Chang-ji line, Changchun, Jilin 130031, P.R. China

E-mail: ozu3ep@163.com

Key words: vitamin D, antituberculosis drugs, pulmonary tuberculosis, immune cells, inflammatory factors that before treatment, while that in RG was significantly lower than that in $\mathrm{CG}(\mathrm{P}<0.05)$. After treatment, soluble selectins in both groups improved significantly. The level of soluble selectins in RG was slightly lower than that in CG. The incidence of adverse reactions in RG was lower than that in CG. The life quality scores of patients in RG were slightly higher than those in $\mathrm{CG}(\mathrm{P}<0.05)$. In conclusion, vitamin $\mathrm{D}$-assisted antituberculosis drugs can effectively improve the immune function and expression level of inflammatory factors in pulmonary tuberculosis patients and reduce adverse reactions.

\section{Introduction}

Pulmonary tuberculosis is mainly an infectious disease caused by Mycobacterium tuberculosis infection. Relevant research data have shown that 10.4 million new cases of tuberculosis occurred worldwide in 2015, and 1.4 million people died of the disease in the same year $(1,2)$. Studies have found that pulmonary tuberculosis is highly infectious and can seriously affect the physical and mental health and quality of life of patients. Some symptoms (expectoration, emaciation and chest pain) are the main clinical manifestations of pulmonary tuberculosis $(3,4)$. In recent years, because of the specific expression of inflammatory factors, immune function cytokines and other related indicators in pulmonary tuberculosis patients, it has become a 'hot spot' in clinical research $(5,6)$.Pulmonary tuberculosis often leads to the decline of immune function. In addition, pulmonary tuberculosis itself is a consumptive disease. Patients often suffer from a decline in immunity. Excessive inflammatory reaction will aggravate the severity of pulmonary tuberculosis and complications, resulting in a poor therapeutic effect $(7,8)$. Therefore, studying the changes in inflammatory factors, immune function and other indicators in the treatment process of pulmonary tuberculosis is helpful for the selection of indicator schemes and treatment.

At present, there are many types of drugs used in the treatment of pulmonary tuberculosis, among which first-line antituberculosis drugs are the first choice, including isoniazid and rifampicin. The treatment scheme combined with multiple drugs is also often used in clinical treatment (9). Literature has demonstrated the effect of rifampicin combined with 
acetylcysteine and vitamin $\mathrm{C}$ on the antibacterial activity of Mycobacterium tuberculosis and Staphylococcus aureus, respectively. It has shown that the combined application of antituberculosis drugs and vitamin $C$ can effectively eradicate microbial infection (10). Vitamin D is an essential nutrient element in human body and belongs to one of the fat-soluble vitamins (11). Recently, it was shown that vitamin D not only plays a role in calcium phosphate and bone metabolism, but also has antibacterial effect (12). Many studies have indicated that the rise in tuberculosis risk is related to deficiency of vitamin D (13). However, there is little research on the effect of vitamin D-assisted anti-tuberculosis drugs on the expression of immune cells and inflammatory factors in patients with pulmonary tuberculosis.

The present study was mainly designed to explore the application value of vitamin D-assisted antituberculosis drugs in pulmonary tuberculosis by detecting the levels of inflammatory factors and immune function in pulmonary tuberculosis patients.

\section{Materials and methods}

Baseline data. A total of 256 patients with pulmonary tuberculosis who were admitted to Changchun Hospital for Infectious Diseases were collected as research participants; 120 patients who were treated with conventional antituberculosis drugs were taken as the control group (CG). There were 66 males and 54 females, with a mean age of $55.66 \pm 6.83$ years (age range, 45-68 years). A total of 136 patients who were treated with vitamin D-assisted antituberculosis drugs were taken as the research group (RG). There were 74 males and 62 females, with a mean age of 54.62 \pm 6.41 years (age range, 42-66 years). The research study was approved by the Ethics Committee of Changchun Hospital for Infectious Diseases (Changchun, Jilin, China). Patients and their families were informed in advance. Informed consent was signed after the consent of all of the participants.

Inclusion criteria. For inclusion into the study, all patients were diagnosed with pulmonary tuberculosis by clinical diagnosis; They were accompanied by family members on admission. There were no other malignant tumors and coronary heart disease diagnosed. The patients did not present with basic diseases before admission, and the body was relatively healthy. The subjects showed tuberculosis toxic symptoms such as cough, hemoptysis and low fever to varying degrees. There were no hematological diseases diagnosed.

Exclusion criteria. Subjects were excluded from the study if they presented with a history of mental diseases, clinical data were incomplete and the subjects did not actively cooperate when they were admitted to the hospital. Patients with severe organ disease or liver dysfunction were excluded. Patient who were allergic to the treatment drug were also exluded.

Therapeutic schemes. Patients in the $\mathrm{CG}$ received anti-tuberculosis treatment and received $0.3 \mathrm{~g} / \mathrm{day}$ of isoniazid orally (Beijing Yongkang Pharmaceutical Co., Ltd.; SFDA approval no. H11020585). Patients were given rifampicin (Beijing Shuguang Pharmaceutical Co., Ltd.; SFDA approval no. H11021062), $0.15 \mathrm{~g}$ once (1 tablet), 3- 4 times a day. Ethambutol (Shanxi Zhendong Taisheng Pharmaceutical Co., Ltd.; SFDA approval no. H14021899) was taken orally once a day at a dose of $15 \mathrm{mg} / \mathrm{kg}$. Pyrazinamide (Ningbo Tianheng Pharmaceutical Co., Ltd.; H33021921) was orally administered at $15-30 \mathrm{mg} / \mathrm{kg}$ daily, or $50-70 \mathrm{mg} / \mathrm{kg}$, 2-3 times a week. Patients were treated continuously for 60 days, and then treated with isoniazid and rifampicin (usage and dosage were the same as above) for 4 months. Patients in the RG received routine antituberculosis drug therapy, supplemented by vitamin $\mathrm{D}$ therapy. During the acute attack of pulmonary tuberculosis, the patient was given 300,000 IU vitamin D3 (Zhejiang Xianju Pharmaceutical Co., Ltd.; SFDA approval no. H20058981) by intramuscular injection. The intervention was implemented once a day, and the specific dose was adjusted according to the actual situation of the patient. Since the patient's pulmonary tuberculosis condition was stable, the patient was given vitamin D3 (Beijing Zizhu Pharmaceutical Co., Ltd.; SFDA approval no. H11022062) for intervention by oral administration with a daily dosage of $0.25 \mathrm{mg}$. All the patients were treated for 6 months.

Index of inspection. Before and after treatment for 3 months, $5 \mathrm{ml}$ of peripheral venous blood of patients in the two groups were collected, respectively, for detection and was centrifuged at 3,000 x $\mathrm{g}$ for $10 \mathrm{~min}$. The serum was stored for later use. HR-801 Enzyme-Labeled Analyzer (Shenzhen Huakerui Technology Co., Ltd.) was used to detect the expression levels of serum inflammatory factors [interleukin (IL)-6, matrix metallopeptidase (MMP)-9, IL-4, tumor necrosis factor (TNF)- $\alpha$ )], surfactant protein (SP-A, SP-D), soluble selectin (sE-seletin, sP-seletin, sL-seletin) in patients in the two groups. The operational steps were strictly carried out in accordance with the instructions outlined in the enzyme-linked immunosorbent assay (ELISA) kits. ELISA kits were purchased from Beijing Baiolebo Technology Co., Ltd. FACSCalibur full-automatic flow cytometer (Becton Dickinson and Flowjo v10.4.2 software (Flowjo LLC) were used to measure the immune function indexes $\left(\mathrm{CD}^{+}, \mathrm{CD}^{+}\right.$, $\left.\mathrm{CD}^{+} / \mathrm{CD}^{+}\right)$of patients in the two groups after operation. Fluorescence coupled monoclonal antibodies $\left(\mathrm{CD}^{+}, \mathrm{CD}^{+}\right.$, $\mathrm{CD}^{+}$) were used to analyze the surface. Extracellular staining was performed according to the manufacturer's instructions. First, the coupled fluorescent antibody (different combination of surface markers) was added to each peripheral blood sample without plasma and incubated in dark for $15 \mathrm{~min}$. Then erythrocyte lysate was added, placed at room temperature for $10 \mathrm{~min}$ and centrifuged at $350 \mathrm{x} \mathrm{g}$ for $5 \mathrm{~min}$, and then the supernatant was discarded to terminate cell lysis. Finally, cells were washed twice with cell staining buffer by $350 \mathrm{x} \mathrm{g}$ centrifugation for $5 \mathrm{~min}$ and the supernatant was discarded. The sample was resuspended in staining buffer in preparation for flow cytometric analysis, in which $\mathrm{CD}^{+}$and $\mathrm{CD} 8^{+} \mathrm{T}$ cells were gated on $\mathrm{CD}^{+}$cells and expressed in lymphocyte percentage.

\section{Evaluation standard}

Efficacy evaluation. For a markedly effective evaluation, the clinical symptoms of the patient disappeared. After continuous sputum examination, the patient was negative. After 
Table I. Comparison of baseline clinical data in the research group (RG) and control group (CG).

\begin{tabular}{|c|c|c|c|c|}
\hline & $\mathrm{RG}(\mathrm{n}=136)$ & $\mathrm{CG}(\mathrm{n}=120)$ & $\mathrm{t} / \chi^{2}$ & P-value \\
\hline Sex & & & 0.009 & 0.925 \\
\hline Male & $74(54.41)$ & $66(55.00)$ & & \\
\hline Female & $62(45.59)$ & $54(45.00)$ & & \\
\hline Mean age (years) & $54.62 \pm 6.41$ & $55.66 \pm 6.83$ & 1.295 & 0.197 \\
\hline Age (years) & & & 0.058 & 0.809 \\
\hline$>50$ & $83(61.03)$ & $75(62.50)$ & & \\
\hline$\leq 50$ & $53(38.97)$ & $45(37.50)$ & & \\
\hline BMI $\left(\mathrm{kg} / \mathrm{m}^{2}\right)$ & $22.84 \pm 2.56$ & $22.94 \pm 2.47$ & 0.317 & 0.752 \\
\hline Education level & & & 0.107 & 0.744 \\
\hline Junior high school or below & $56(41.18)$ & $47(39.17)$ & & \\
\hline High school or above & $80(58.82)$ & $73(60.83)$ & & \\
\hline Average duration of disease (months) & $5.01 \pm 2.13$ & $4.97 \pm 2.32$ & 0.144 & 0.886 \\
\hline Smoking & & & 0.204 & 0.651 \\
\hline Yes & $87(63.97)$ & $80(66.67)$ & & \\
\hline No & $49(36.03)$ & $40(33.33)$ & & \\
\hline Household registration & & & 0.031 & 0.861 \\
\hline Resident population & $79(58.09)$ & $71(59.17)$ & & \\
\hline Floating population & $57(41.91)$ & $49(40.83)$ & & \\
\hline
\end{tabular}

Data are expressed as (mean $\pm \mathrm{SD})$ or $\mathrm{n}(\%)$. BMI, body mass index.

imaging examination, it was found that the lesion site had disappeared, the lesion was obviously narrowed and the cavity was closed. For an effective evaluation, the clinical symptoms of the patient were significantly improved. The sputum examination results turned negative. After examination, it was found that the lesion site had significantly disappeared, the lesion was reduced and the cavity was basically closed. For an ineffective evaluation, the patient's sputum examination was positive, the lesion was not significantly improved, and the cavity was enlarged or a new cavity appeared. Total effective rate $1 \%=$ markedly effective $1 \%+$ effective $1 \%$.

Outcome measures. The improvement of symptoms after treatment was compared between the two groups. The X-ray chest plain film and sputum examination results were observed in the two groups. The related factors (inflammatory factors, immune cytokines) were detected in the two groups. In the treatment process, the occurrence of adverse reactions were classified and counted in the two groups, and the adverse reaction rates in the treatment process were compared in the two groups. According to SF-36 quality of life score (14), the living standards of the two groups were compared after treatment.

Statistical methods. SPSS v19.0 (Asia Analytics formerly SPSS) was used in this study. The counting data are expressed as [n (\%)]. The Chi-square test was used for inter-group comparison. The measurement data are expressed as [mean \pm standard deviation (SD)]. t-test was used to compare two groups. Repetitive measurement and analysis of variance was used to analyze multiple groups. LSD-t test was used for back testing. $\mathrm{P}<0.05$ was considered to indicate a statistically significant difference.

\section{Results}

Comparison of baseline clinical data in both groups. The baseline clinical data of patients in the two groups were statistically analyzed, as shown in Table I. There were no significant differences in sex, age, body mass index (BMI), education level, average duration, smoking or not and household registration of patients between the two groups, which were comparable $(\mathrm{P}>0.05)$.

Comparison of improvement time of clinical symptoms in the two groups. According to the results in Table II, the disappearance time of wheezing and cough in $\mathrm{RG}$ was shorter than that in $C G(P<0.001)$, while the disappearance time of pulmonary rales was not significantly different in the two groups $(\mathrm{P}>0.05)$.

Comparison of $X$-ray chest plain film and sputum examination results of patients in the two groups. Through X-ray chest plain film and sputum examination, it was found (Table III) that patients in the two groups had improvements in the number of cavity closure, lesion absorption and the sputum examinations were negative. There were no significant differences in examination results between the two groups $(\mathrm{P}>0.05)$.

Comparison of the efficacy of treatment in the two groups. Following comparison of the efficacy of patients in the RG and CG groups after treatment, it was found (Fig. 1) that there were 67 cases with markedly effective results, 58 cases with effective results and 11 cases with ineffective results, with a 
Table II. Comparison of improvement time (days) of clinical symptoms in the research group (RG) and the control group (CG).

\begin{tabular}{lccc}
\hline & $\begin{array}{c}\text { Disappearance time } \\
\text { of pulmonary rales }\end{array}$ & $\begin{array}{c}\text { Disappearance time } \\
\text { of cough }\end{array}$ & $\begin{array}{c}\text { Disappearance time } \\
\text { of wheezing }\end{array}$ \\
\hline $\mathrm{RG}(\mathrm{n}=136)$ & $5.78 \pm 1.34$ & $4.02 \pm 1.65$ & $3.97 \pm 1.51$ \\
$\mathrm{CG}(\mathrm{n}=120)$ & $6.10 \pm 1.72$ & $5.24 \pm 1.33$ & $5.86 \pm 1.45$ \\
$\mathrm{t}$ & 1.670 & 6.457 & 10.180 \\
$\mathrm{P}$-value & 0.096 & $<0.001$ & $<0.001$ \\
\hline
\end{tabular}

Data are expressed as mean \pm SD days.

Table III. Comparison of the X-ray chest plain film and sputum examination results of the patients in the research group (RG) and control group (CG).

\begin{tabular}{lccc}
\hline & $\begin{array}{c}\text { No. of cavity } \\
\text { closures }\end{array}$ & $\begin{array}{c}\text { No. of lesion } \\
\text { absorptions }\end{array}$ & $\begin{array}{c}\text { No. of sputum examination } \\
\text { turning negative }\end{array}$ \\
\hline RG $(n=136)$ & $125(91.91)$ & $124(91.18)$ & $126(92.65)$ \\
CG $(n=120)$ & $106(88.33)$ & $107(89.17)$ & $109(90.83)$ \\
$\chi^{2}$ & 0.926 & 0.292 & 0.279 \\
P-value & 0.336 & 0.589 & 0.598 \\
\hline
\end{tabular}

Data are expressed as $\mathrm{n}(\%)$.

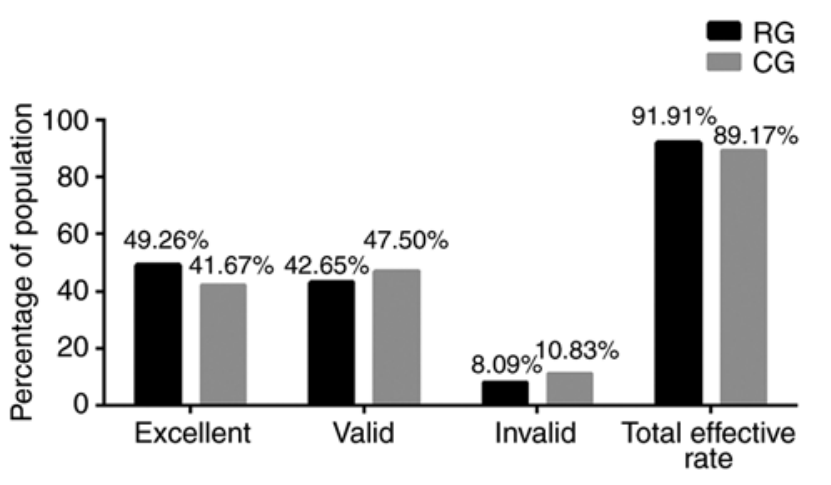

Figure 1. Comparison of efficacy in the RG and CG. The total effective rate in RG was $91.91 \%$, while that of CG was $89.17 \%$. There was no significant difference in the total effective rate between the two groups $(\mathrm{P}>0.05)$. RG, $\mathrm{n}=136, \mathrm{CG}, \mathrm{n}=120 . \mathrm{RG}$, research group; CG, control group.

total effective rate of $91.91 \%$ in $\mathrm{RG}$, while there were 50 cases with markedly effective results, 57 cases with effective results and 13 cases with ineffective results, with a total effective rate of $89.17 \%$ in CG. There was no significant difference in total effective rate between the two groups $(\mathrm{P}>0.05)$.

Comparison of immune cytokines in the two groups. Comparing the changes of immune function indexes between the RG and $\mathrm{CG}$ after different treatment methods, it was found that there were no significant differences in immune function indexes between the two groups before treatment $(\mathrm{P}>0.05)$. After treatment, the immune function indexes of the two groups were both upregulated $(\mathrm{P}<0.05)$, while $\mathrm{CD}^{+}, \mathrm{CD}^{+}, \mathrm{CD} 4^{+} / \mathrm{CD}^{+}$in the $\mathrm{RG}$ were significantly higher than those in the $\mathrm{CG}(\mathrm{P}<0.05$; Fig. 2$)$.
Comparison of levels of inflammatory factors in the two groups. Following comparison of the changes in inflammatory factors between the RG and CG after different treatment methods, it was found that there were no significant differences in the levels of inflammatory factors before treatment between the two groups. After treatment, the inflammatory factors in the two groups were improved compared with those before treatment. Serum inflammatory factors (IL-6, MMP-9, IL-4, TNF- $\alpha$ ) in RG were significantly lower than those in CG $(\mathrm{P}<0.05$; Fig. 3).

Comparison of surfactant proteins in the two groups. Following comparison of the changes of surfactant protein in the RG and CG after different treatment methods, there was no difference in the comparison of surfactant protein between the two groups before treatment $(\mathrm{P}>0.05)$. After treatment, the surfactant protein in the two groups was lower than that before treatment, while SP-A and SP-D in RG were significantly lower than those in $\mathrm{CG}(\mathrm{P}<0.05$; Fig. 4).

Comparison of levels of soluble selectins in the two groups. Following comparison of the levels of soluble selectins (sE-seletin, sP-seletin, sL-seletin) before and after treatment in the RG and CG (Fig. 5), it was found that there was no significant difference between the two groups before treatment $(\mathrm{P}>0.05)$. After treatment, soluble selectins improved significantly in the both groups. The levels of soluble selectins in RG were slightly lower than those in $\mathrm{CG}$, while the levels of sP-seletin in $\mathrm{RG}$ were significantly lower than those in $\mathrm{CG}(\mathrm{P}<0.05)$.

Comparison of adverse reactions in the two groups. Adverse reactions of patients during treatment was counted, as shown 
Table IV. Comparison of adverse reactions in the research group (RG) and control group (CG).

\begin{tabular}{lcccccc}
\hline & $\begin{array}{c}\text { Nausea and } \\
\text { vomiting }\end{array}$ & Fever & $\begin{array}{c}\text { Gastrointestinal } \\
\text { reaction }\end{array}$ & Rash & Dizziness & $\begin{array}{c}\text { Overall } \\
\text { incidence }\end{array}$ \\
\hline RG $(\mathrm{n}=136)$ & $4(2.94)$ & $3(2.21)$ & $6(4.41)$ & $1(0.74)$ & $7(5.15)$ & $15.45 \%$ \\
CG $(\mathrm{n}=120)$ & $6(5.00)$ & $5(4.17)$ & $8(6.67)$ & $3(2.50)$ & $9(7.50)$ & $25.84 \%$ \\
$\chi^{2}$ & & & & & & 4.253 \\
P-value & & & & & & 0.039 \\
\hline
\end{tabular}

Data are expressed as n (\%).
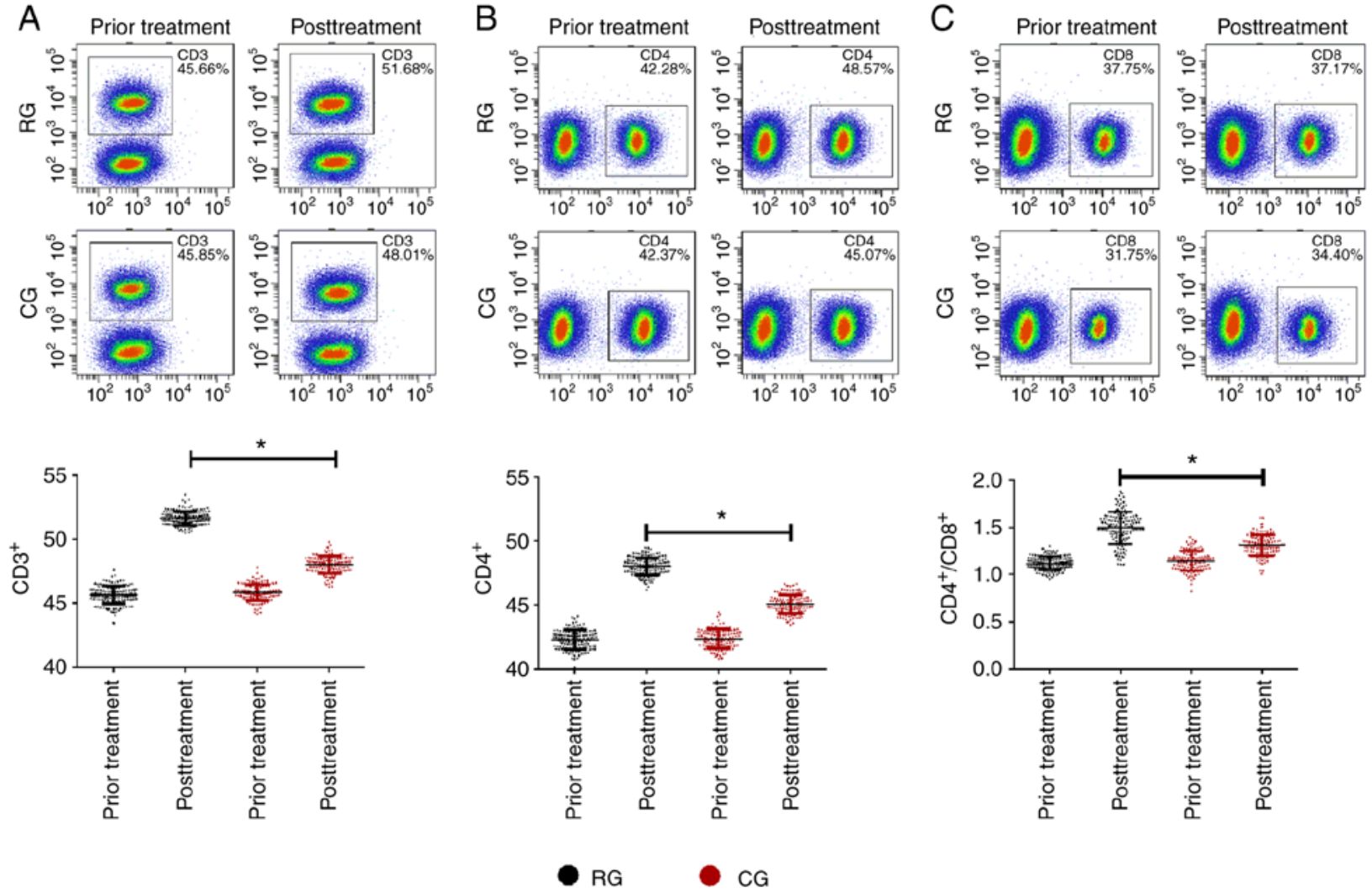

Figure 2. Comparison of immune function indexes in the RG and CG. (A) Comparison of $\mathrm{CD}^{+}$levels before and after treatment in the RG and CG. (B) Comparison of $\mathrm{CD} 4^{+}$levels before and after treatment in the RG and CG. (C) Comparison of $\mathrm{CD}^{+} / \mathrm{CD} 8^{+}$levels before and after treatment in the RG and CG. "P<0.05, significant difference between the two groups. RG, $n=136, C G, n=120$. RG, research group; CG, control group.

in Table IV. It could be found that the incidence of adverse reactions in $\mathrm{RG}$ was lower than that in $\mathrm{CG}(15.45 \%$ vs. $25.84 \%)$.

Comparison of life quality score in the two groups. The life quality score in the RG and CG were statistically recorded. There was no difference in the two groups before treatment. After different treatments, the life quality score were significantly improved in the two groups, and the life quality score of patients in $\mathrm{RG}$ were significantly higher than those in $\mathrm{CG}$ $(\mathrm{P}<0.05$; Fig. 6).

\section{Discussion}

Pulmonary tuberculosis is a chronic infectious disease transmitted through the respiratory system (15). At present, pulmonary tuberculosis is still a global health problem with a huge disease burden. In the new cases of pulmonary tuberculosis, $10 \%$ are children and $12 \%$ are human immunodeficiency virus (HIV) co-infection with high mortality rate $(16,17)$. Therefore, pulmonary tuberculosis has become the main cause of death from infectious diseases. Common drugs for the treatment of pulmonary tuberculosis include rifampicin, ethambutol, isoniazid and pyrazinamide. Although isoniazid and ethambutol have ideal therapeutic effects, resistance of drugs will appear after long-term use, resulting in drug resistance. The therapeutic effect of pyrazinamide is easily affected by $\mathrm{pH}$ value. Therefore, when the $\mathrm{pH}$ value is slightly acidic, the drug has a better curative effect (18-21). Rifampicin has better antibacterial activity, but there are many adverse reactions after long-term use (18-21). Therefore, at present, most 
A

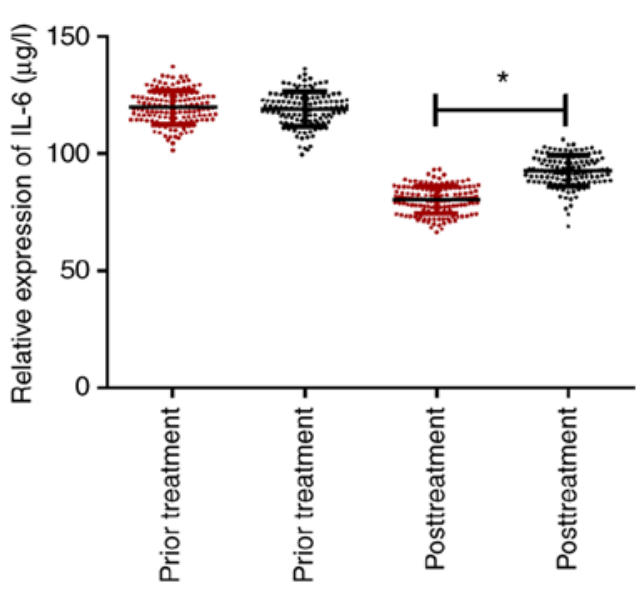

B

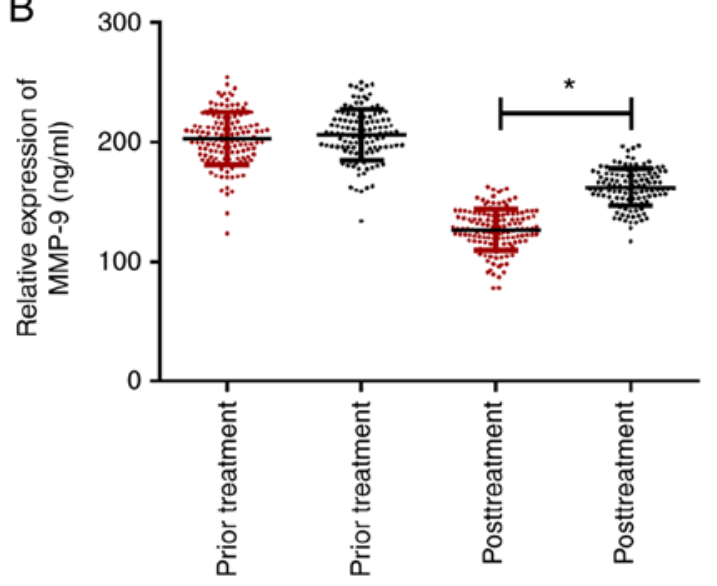

$R G \bigcirc C G$
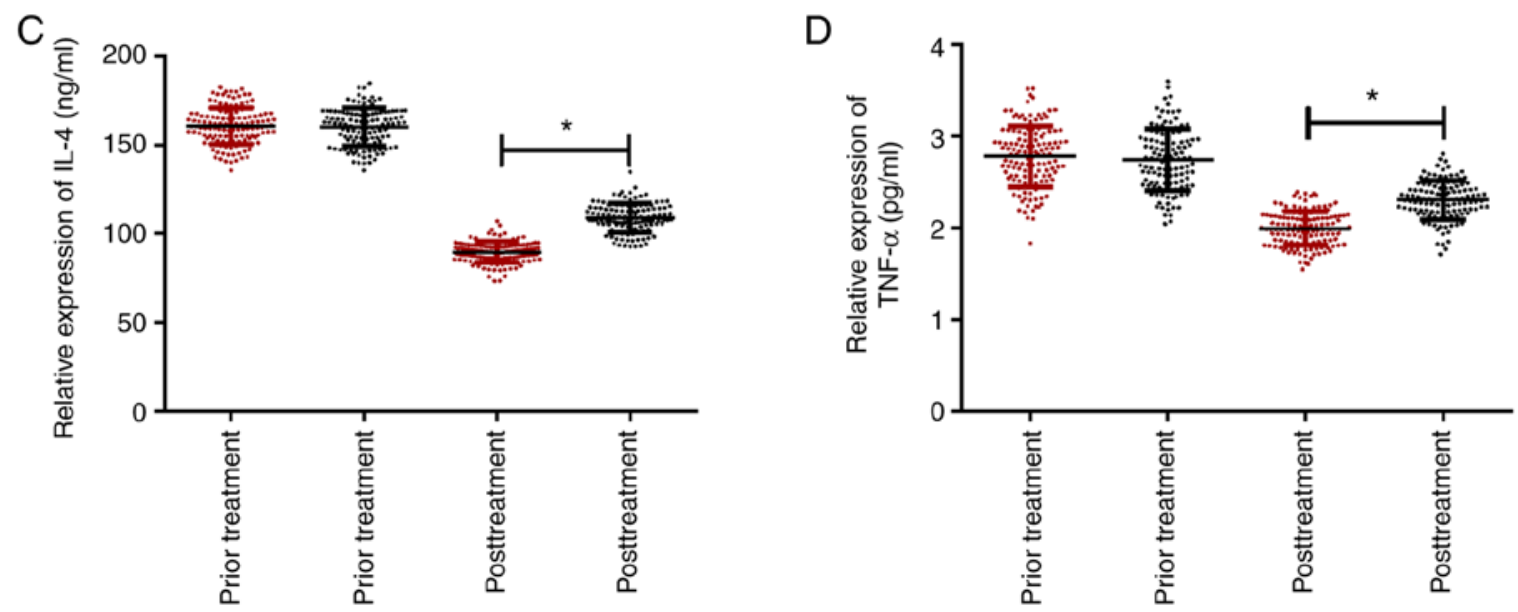

Figure 3. Comparison of levels of inflammatory factors in the RG and CG. (A) Comparison of levels of inflammatory factor IL-6 before and after treatment in the RG and CG. (B) Comparison of levels of inflammatory factor MMP-9 before and after treatment in the RG and CG. (C) Comparison of levels of inflammatory factor IL-4 before and after treatment in the RG and CG. (D) Comparison of levels of inflammatory factor TNF- $\alpha$ before and after treatment in the RG and CG. ${ }^{*} \mathrm{P}<0.05$, significant difference between the two groups. RG, $\mathrm{n}=136, \mathrm{CG}, \mathrm{n}=120$. RG, research group; CG, control group; IL, interleukin; MMP, matrix metallopeptidase; TNF, tumor necrosis factor.
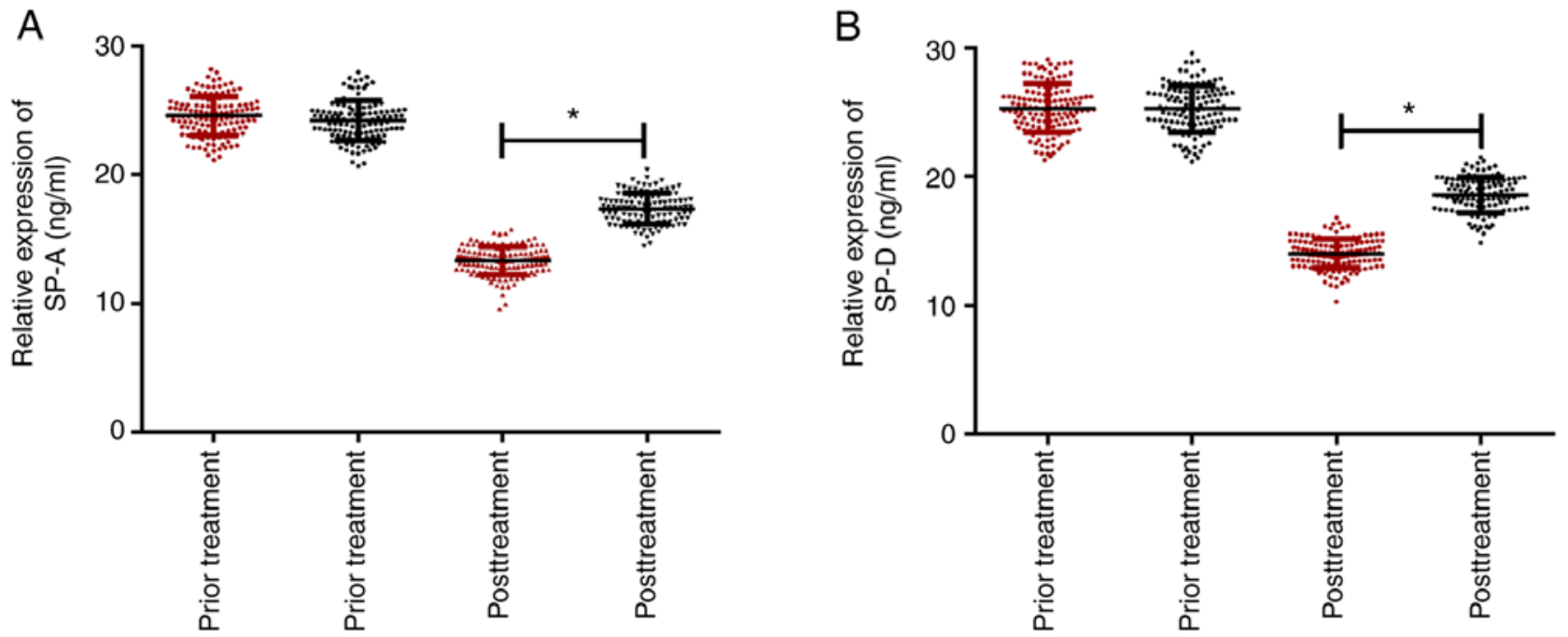
A

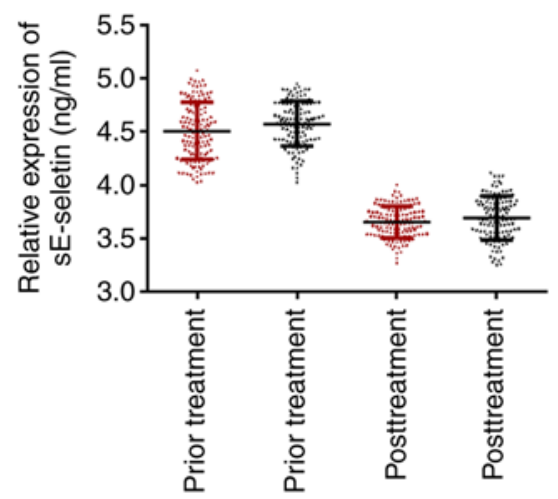

B

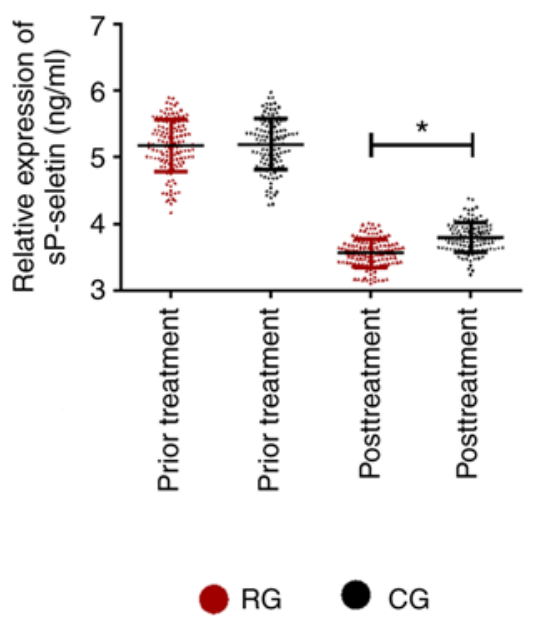

C

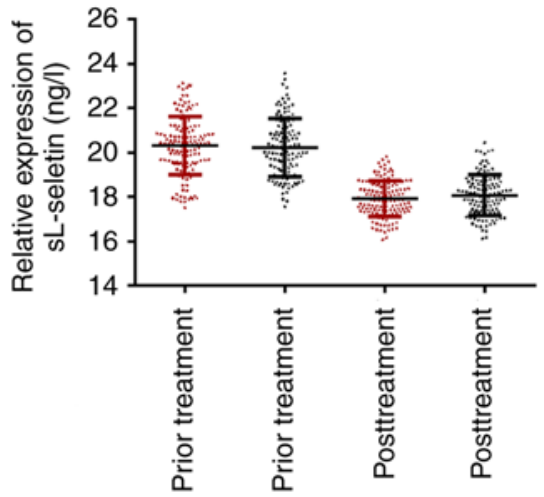

Figure 5. Comparison of levels of soluble selectins in the RG and CG. (A) Comparison of soluble selectin sE-seletin levels in the RG and CG. (B) Comparison of soluble selectin sP-seletin levels in the RG and CG. (C) Comparison of soluble selectin sL-seletin levels in the RG and CG. "P<0.05, significant difference between the two groups. $\mathrm{RG}, \mathrm{n}=136, \mathrm{CG}, \mathrm{n}=120$. RG, research group; $\mathrm{CG}$, control group.

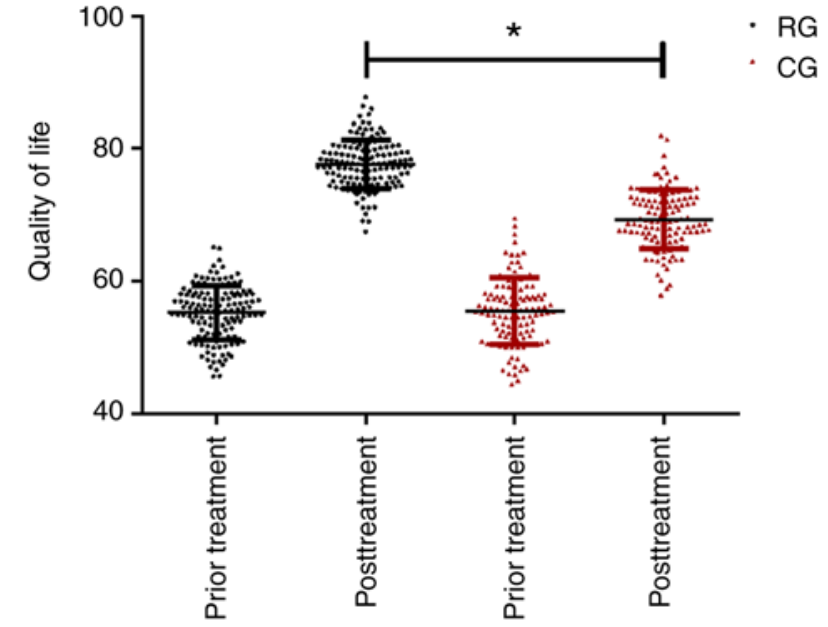

Figure 6. Comparison of life quality score in the RG and CG. After different treatments, the life quality score were significantly improved in the two groups, and the life quality scores of patients in the RG were slightly higher than those in the CG $(\mathrm{P}<0.05)$. ${ }^{*} \mathrm{P}<0.05$, significant difference between the two groups. $R G, n=136, C G, n=120$. $R G$, research group; $C G$, control group.

of the patients with pulmonary tuberculosis are treated with a combination of drugs, which can significantly improve the inflammatory levels and quality of life of patients (22).

Pulmonary tuberculosis is often accompanied by typical respiratory symptoms. The signs are not very obvious in the early stage, but obvious moist rales, increased vocal fremitus and percussion dullness can be found in the middle and late stages $(23,24)$. The results of the present study indicated that both treatment methods improved the clinical symptoms of pulmonary tuberculosis patients, and the effect was better with vitamin D supplementation. In addition, the therapeutic effects were also compared in the research group (RG) and control group (CG) in this study. The results indicated that both treatment methods improved the number of cavity closures, lesion absorption and the sputum examination results turned negative, but there was no significant difference in efficacy between the two groups. Studies have indicated no improvement in clinical parameters (mortality, sputum smear positivity and sputum culture positivity) in patients with pulmonary tuberculosis compared to placebo (25). Since this study mainly focused on the short-term efficacy of patients and did not deal with the long-term efficacy, the effect of vitamin D on the efficacy of pulmonary tuberculosis patients needs to be confirmed by a large number of studies. T lymphocyte subsets are one type of human immune response cells and is an important cell tissue of the body's immune system. $\mathrm{CD}^{+}$is expressed in $\mathrm{T}$ cells and it is also the basis of the body's cellular immunity. $\mathrm{CD}^{+}$is considered to be helper $\mathrm{T}(\mathrm{Th})$ cells, and $\mathrm{CD} 4^{+} / \mathrm{CD}^{+}$ can reflect cellular immune dysfunction, thus the level of $\mathrm{T}$ cell subsets can fully reflect the body's immune function and degree of disease development (26-28). In the literature, it has been reported that vitamin $\mathrm{D}$ is a key regulator for host defense against infection in patients infected with human HIV (29). In combination of the enhancement of innate and adaptive immunity by activating genes and pathways, supplementation of vitamin D and restoring it to a normal value can improve immune recovery during antiretroviral therapy, reduce inflammation and immune activation levels, and improve immunity to pathogens (29). The present study revealed that there was no significant difference in immune function indexes in the RG and $\mathrm{CG}$ before treatment. After treatment, immune function indexes were upregulated in both groups, while $\mathrm{CD}^{+}, \mathrm{CD}^{+}$, $\mathrm{CD}^{+} / \mathrm{CD}^{+}$in the $\mathrm{RG}$ were higher than those in the $\mathrm{CG}$. The results suggest that vitamin $\mathrm{D}$ assistance could alleviate the immune dysfunction of pulmonary tuberculosis patients. Interleukin (IL-6), matrix metalloproteinase (MMP)-9, IL-4 and tumor necrosis factor (TNF)- $\alpha$ are important inflammatory factors with strong biological effects, which can participate in the regulation of immune response and are upregulated when the body is in a pathological state $(30,31)$. Vitamin D has been shown to inhibit pro-inflammatory cytokine responses and enhance anti-inflammatory responses (32). This study revealed that the levels of IL-6, MMP-9, IL-4 and TNF- $\alpha$ were significantly reduced after vitamin D adjuvant 
treatment, and the therapeutic effect was more obvious than that of conventional antituberculosis drugs.

Serum SP-A and SP-D belong to surfactant proteins and have been confirmed to be useful biomarkers for the severity of pneumonia, chronic obstructive pulmonary disease and tuberculosis. They are highly expressed in pulmonary diseases $(33,34)$. The present study was designed to compare the content of surfactant protein before and after treatment in the RG and CG. Both treatment methods improved the content of surfactant protein after treatment, and vitamin D auxiliary treatment effectively reduced the levels of SP-A and SP-D. Animal experimental research has revealed that SP-D levels in mice with sufficient vitamin D before and after infection are lower than those in mice with insufficient vitamin D (35). Since the serum level of the patients was tested in this study at 3 months after treatment, we did not know the long-term changing trend of surfactant protein, thus the effect of vitamin D on the content of surfactant protein still needs further research to confirm the long-term impact. Soluble selectin (sE-seletin, sP-se-letin, sL-seletin) is highly expressed in patients with pulmonary tuberculosis, which may be related to pulmonary inflammatory stress of the patient $(36,37)$, thus regulating its expression has high value in the diagnosis and treatment of diseases. The results of the present study showed that both treatments improved the level of soluble selectins and regulated the inflammatory stress state of pulmonary tuberculosis patients. A related meta-analysis (a study of children) showed that vitamin D supplementation had no beneficial effect on improving sputum smear, culture transformation and adverse reactions in children with pulmonary tuberculosis (38). In the present study, the total incidence of adverse reactions in RG was relatively low. It may be that vitamin D plays an auxiliary role and it effectively relieved the occurrence of various adverse reactions. Many studies have shown that adequate vitamin D supplementation can improve the quality of life of patients presenting with various diseases. For example, Bai and Dai (39) proposed that increased serum vitamin $\mathrm{A}$ and 25 -hydroxyvitamin $\mathrm{D} 3\left(25 \mathrm{OHD}_{3}\right)$ levels can reflect the lung function and quality of life of asthmatic children. Vitamin D supplementation can improve the quality of life of patients with chronic pulmonary obstruction (40). In this study, quality of life scores were observed and counted in the RG and CG. It was found that the use of vitamin D combined with antituberculosis drugs significantly improved the quality of life of the pulmonary tuberculosis patients, and had better application value.

In the present study, the application value of vitamin D-assisted antituberculosis drug treatment in tuberculosis patients was compared from several aspects. Due to the short follow-up period in this study, it was not possible to follow up the long-term efficacy of patients, changes in immune cells and inflammatory factors, thus there are certain limitations. In the future, we can strengthen the research in this direction and further study the complex factors affecting the efficacy of tuberculosis treatment.

To sum up, vitamin D-assisted antituberculosis drugs can effectively improve the immune function indexes and expression level of inflammatory factors in pulmonary tuberculosis patients and reduce the adverse reactions associated with treatment.

\section{Acknowledgements}

Not applicable.

\section{Funding}

No funding was received.

\section{Availability of data and materials}

The datasets used and/or analyzed during the present study are available from the corresponding author on reasonable request.

\section{Authors' contributions}

CC conceived the research design and wrote the manuscript. WP and XL were responsible for the treatment and evaluation. HQ performed statistical analysis and designed the tables and figures. All authors read and approved the manuscript and agree to be accounTable for all aspects of the research in ensuring that the accuracy or integrity of any part of the work are appropriately investigated and resolved.

\section{Ethics approval and consent to participate}

The study was approved by the Ethics Committee of Changchun Hospital for Infectious Diseases (Changchun, Jilin, China). Patients who participated in this research, signed the informed consent and had complete clinical data. Signed written informed consents were obtained from the patients and/or guardians.

\section{Patient consent for publication}

Not applicable.

\section{Competing interests}

The authors declare that they have no competing interests.

\section{References}

1. Guo Z, Xiao D, Wang X, Wang Y and Yan T: Epidemiological characteristics of pulmonary tuberculosis in mainland China from 2004 to 2015: A model-based analysis. BMC Public Health 19: 219, 2019.

2. Xu Y, Wu J, Liao S and Sun Z: Treating tuberculosis with high doses of anti-TB drugs: Mechanisms and outcomes. Ann Clin Microbiol Antimicrob 16: 67, 2017.

3. Carvalho AC, Cardoso CA, Martire TM, Migliori GB and Sant'Anna CC: Epidemiological aspects, clinical manifestations, and prevention of pediatric tuberculosis from the perspective of the end TB strategy. J Bras Pneumol 44: 134-144, 2018 (In Portuguese, English).

4. Rao VG, Bhat J, Yadav R, Muniyandi M, Bhondeley MK and Wares DF: Yield of pulmonary tuberculosis cases by symptoms: Findings from a community survey in Madhya Pradesh, central India. Indian J Tuberc 62: 121-123, 2015.

5. Shen X, Zhang J, Tang P, Song H, Liu X, Huang Z, Zhang X, Wang $X$ and Wu M: Expression and clinical significance of $B$ and T lymphocyte attenuator on $\mathrm{CD} 4^{+}$and $\mathrm{CD} 8^{+} \mathrm{T}$ cells from patients with pulmonary tuberculosis. Indian J Pathol Microbiol 62: 232-238, 2019.

6. Peng X, Luo T, Zhai X, Zhang C, Suo J, Ma P, Wang C and Bao L: PPE11 of Mycobacterium tuberculosis can alter host inflammatory response and trigger cell death. Microb Pathog 126: 45-55, 2019. 
7. Rekha RS,Mily A,Sultana T,Haq A,Ahmed S,Mostafa Kamal SM, van Schadewijk A, Hiemstra PS, Gudmundsson GH, Agerberth B and Raqib $R$ : Immune responses in the treatment of drug-sensitive pulmonary tuberculosis with phenylbutyrate and vitamin $\mathrm{D}_{3}$ as host directed therapy. BMC Infect Dis 18: 303, 2018.

8. Tomio J, Yamana H, Matsui H, Yamashita H, Yoshiyama T and Yasunaga H: Tuberculosis screening prior to anti-tumor necrosis factor therapy among patients with immune-mediated inflammatory diseases in Japan: A longitudinal study using a large-scale health insurance claims database. Int J Rheum Dis 20: 1674-1683, 2017.

9. Tornheim JA and Dooley KE: The global landscape of tuberculosis therapeutics. Annu Rev Med 70: 105-120, 2019.

10. Khameneh B, Fazly Bazzaz BS, Amani A, Rostami J and Vahdati-Mashhadian N: Combination of anti-tuberculosis drugs with vitamin $\mathrm{C}$ or NAC against different Staphylococcus aureus and Mycobacterium tuberculosis strains. Microb Pathog 93: 83-87, 2016.

11. Zittermann A: Vitamin D in preventive medicine: Are we ignoring the evidence? Br J Nutr 89: 552-572, 2003.

12. Syal K, Chakraborty S, Bhattacharyya R and Banerjee D: Combined inhalation and oral supplementation of Vitamin A and Vitamin D: A possible prevention and therapy for tuberculosis. Med Hypotheses 84: 199-203, 2015.

13. Huang SJ, Wang XH, Liu ZD, Cao WL, Han Y, Ma AG and Xu SF: Vitamin D deficiency and the risk of tuberculosis: A meta-analysis. Drug Des Devel Ther 11: 91-102, 2016.

14. Li CT, Chu KH, Reiher B, Kienene T and Chien LY: Evaluation of health-related quality of life in patients with tuberculosis who completed treatment in Kiribati. J Int Med Res 45: 610-620, 2017

15. Ossalé Abacka KB, Koné A, Akoli Ekoya O, Bopaka RG, Lankoandé Siri $\mathrm{H}$ and Horo K: Extrapulmonary tuberculosis versus pulmonary tuberculosis: Epidemiological, diagnosis and evolutive aspects. Rev Pneumol Clin 74: 452-457, 2018 (In French).

16. Maitra A, Kamil TK, Shaik M, Danquah CA, Chrzastek A and Bhakta S: Early diagnosis and effective treatment regimens are the keys to tackle antimicrobial resistance in tuberculosis (TB): A report from Euroscicon's international TB Summit 2016. Virulence 8: 1005-1024, 2017.

17. Churchyard G, Kim P, Shah NS, Rustomjee R, Gandhi N, Mathema B, Dowdy D, Kasmar A and Cardenas V: What we know about tuberculosis transmission: An overview. J Infect Dis 216 (suppl 6): S629-S635, 2017.

18. Reynolds IR and Chan ED: An update on the trends and treatment in multidrug-resistant tuberculosis. Am J Respir Crit Care Med 193: A5533-A5533, 2016.

19. An J, Bai X, Gao M, Chu N, Huang H, Xu H, Zhang X, Li B, Huang C, Cai H, et al: Antituberculosis drug prescribing for inpatients in a national tuberculosis hospital in China, 2011-2015. J Glob Antimicrob Resist 14: 17-22, 2018.

20. Gegia M, Winters N, Benedetti A, van Soolingen D and Menzies D: Treatment of isoniazid-resistant tuberculosis with first-line drugs: A systematic review and meta-analysis. Lancet Infect Dis 17: 223-234, 2017.

21. Hu Y, Wu X, Luo J, Fu Y, Zhao L, Ma Y, Li Y, Liang Q, Shang $\mathrm{Y}$ and Huang $\mathrm{H}$ : Detection of pyrazinamide resistance of Mycobacterium tuberculosis using nicotinamide as a surrogate. Clin Microbiol Infect 23: 835-838, 2017.

22. Alessandra C Pinheiro and Marcus V N de Souza: The relevance of new drug combinations for modern tuberculosis treatment-a patent perspective. Recent Pat Antiinfect Drug Discov 8: 130-138, 2013

23. Li C, Liu L and Tao Y: Diagnosis and treatment of congenital tuberculosis: A systematic review of 92 cases. Orphanet J Rare Dis 14: 131, 2019.

24. Lewinsohn DM, Leonard MK, LoBue PA, Cohn DL, Daley CL, Desmond E, Keane J, Lewinsohn DA, Loeffler AM, Mazurek GH,et al: Official American Thoracic Society/Infectious Diseases Society of America/Centers for disease control and prevention clinical practice guidelines: Diagnosis of tuberculosis in adults and children. Clin Infect Dis 64: e1-e33, 2017.

25. Haris R, Irbaz R, Tanvir A, Maaz B and Abul M: Vitamin D as a supplementary agent in the treatment of pulmonary tuberculosis: A systematic review and meta-analysis of randomized controlled trials. Eur Respir J 42: 4623, 2013
26. Li C, Zhou HC, Nie YL, Zhao BY and Wu CC: Effects of lipopolysaccharide on $\mathrm{T}$ lymphocyte cell subsets and cytokine secretion in mesenteric lymph nodes of mice: Histological and molecular study. Environ Toxicol Pharmacol 71: 103214, 2019.

27. Pérez-Antón E, Egui A, Thomas MC, Puerta CJ, González JM, Cuéllar A, Segovia M and López MC: Impact of benznidazole treatment on the functional response of Trypanosoma cruzi antigen-specific $\mathrm{CD} 4{ }^{+} \mathrm{CD} 8{ }^{+} \mathrm{T}$ cells in chronic Chagas disease patients. PLoS Negl Trop Dis 12: e0006480, 2018.

28. Muller L, Mitsuhashi M, Simms P, Gooding WE and Whiteside TL: Tumor-derived exosomes regulate expression of immune function-related genes in human T cell subsets. Sci Rep 6: 20254, 2016.

29. Jiménez-Sousa MÁ, Martínez I, Medrano LM, Fernández-Rodríguez A and Resino S: Vitamin D in human immunodeficiency virus infection: Influence on immunity and disease. Front Immunol 9: 458, 2018.

30. Naik SP, Mahesh PA, Jayaraj BS, Madhunapantula SV, Jahromi SR and Yadav MK: Evaluation of inflammatory markers interleukin-6 (IL-6) and matrix metalloproteinase-9 (MMP-9) in asthma. J Asthma 54: 584-593, 2017.

31. Acharya AB, Thakur S, Muddapur MV and Kulkarni RD: Tumor necrosis factor- $\alpha$, interleukin- 4 and -6 in the serum of health, chronic periodontitis, and type 2 diabetes mellitus. J Indian Soc Periodontol 20: 509-513, 2016.

32. Selvaraj P, Harishankar M and Afsal K: Vitamin D: Immuno-modulation and tuberculosis treatment. Can J Physiol Pharmacol 93: 377-384, 2015.

33. Güzel A, Karadağ A, Okuyucu A, Alaçam H and Küçük Y: The evaluation of serum surfactant protein D (SP-D) levels as a biomarker of lung injury in tuberculosis and different lung diseases. Clin Lab 60: 1091-1098, 2014.

34. Enomoto Y, Hagiwara E, Komatsu S, Nishihira R, Baba T and Ogura T: Comparison of biomarkers of pulmonary tuberculosis activity-serum surfactant proteins A and D, KL-6, C-reactive protein, and erythrocyte sedimentation rate. Kekkaku 89: 637-642, 2014 (In Japanese).

35. Serré J, Mathyssen C, Ajime TT, Korf H, Maes K, Heulens N, Gysemans C, Mathieu C, Vanaudenaerde B, Janssens W and Gayan-Ramirez G: Data on inflammatory cytokines and pathways involved in clearance of nontypeable Haemophilus influenzae from the lungs during cigarette smoking and vitamin D deficiency. Data Brief 22: 703-708, 2018.

36. Mukae H, Ashitani J, Tokojima M, Ihi T, Kohno S and Matsukura S: Elevated levels of circulating adhesion molecules in patients with active pulmonary tuberculosis. Respirology 8 : 326-331, 2003

37. Nowak JK, Wojsyk-Banaszak I, Madry E, Wykretowicz A, Krzyżanowska P, Drzymała-Czyż S, Nowicka A, Pogorzelski A, Sapiejka E, Skorupa W, et al: Increased soluble VCAM-1 and normal P-selectin in cystic fibrosis: A cross-sectional study. Lung 195: 445-453, 2017.

38. Xia J, Shi L, Zhao L and Xu F: Impact of vitamin D supplementation on the outcome of tuberculosis treatment: A systematic review and meta-analysis of randomized controlled trials. Chin Med J (Engl) 127: 3127-3134, 2014.

39. Bai YJ and Dai RJ: Serum levels of vitamin A and 25-hydroxyvitamin D3 $\left(25 \mathrm{OHD}_{3}\right)$ as reflectors of pulmonary function and quality of life (QOL) in children with sTable asthma: A case-control study. Medicine (Baltimore) 97: e9830, 2018

40. Alavi Foumani A, Mehrdad M, Jafarinezhad A, Nokani K and Jafari A: Impact of vitamin D on spirometry findings and quality of life in patients with chronic obstructive pulmonary disease: A randomized, double-blinded, placebo-controlled clinical trial. Int J Chron Obstruct Pulmon Dis 14: 1495-1501, 2019.

This work is licensed under a Creative Commons Attribution-NonCommercial-NoDerivatives 4.0 International (CC BY-NC-ND 4.0) License. 